This manuscript is contextually identical with the following published paper: Bácsi I., Deli J., Gonda S., Mészáros I., Veréb G., Dobronoki D., Nagy S.A., B-Béres V., Vasas G. (2018): Non-steroidal anti-inflammatory drugs initiate morphological changes but inhibit carotenoid accumulation in Haematococcus pluvialis. Algal Research 31C: 1-13. https://doi.org/10.1016/j.algal.2018.01.007 The original published PDF available in this website: https://www.sciencedirect.com/science/article/pii/S2211926417307774

\title{
Non-steroidal anti-inflammatory drugs initiate morphological changes but inhibit carotenoid accumulation in Haematococcus pluvialis
}

István Bácsi ${ }^{1 *}$, József Deli ${ }^{2,3}$, Sándor Gonda ${ }^{4}$, Ilona Mészáros ${ }^{5}$, Gréta Veréb ${ }^{6}$, Dalma Dobronoki ${ }^{1}$, Sándor Alex Nagy ${ }^{1}$, Viktória B-Béres ${ }^{7,8}$, Gábor Vasas ${ }^{4}$

${ }^{1}$ University of Debrecen, Department of Hydrobiology, P.O. Box 57, H-4010 Debrecen, Hungary

${ }^{2}$ University of Pécs, Faculty of Pharmacy, Department of Pharmacognosy, Rókus str 2, H7624 Pécs, Hungary

${ }^{3}$ University of Pécs, Medical School, Department of Biochemistry and Medical Chemistry, Szigeti str 12, H-7624 Pécs, Hungary

${ }^{4}$ University of Debrecen, Department of Botany, Division of Pharmacognosy, P.O. Box 14, H-4010 Debrecen, Hungary

${ }^{5}$ University of Debrecen, Department of Botany, P.O. Box 14, H-4010 Debrecen, Hungary

${ }^{6}$ Borsod-Abaúj-Zemplén County Government Office Városház sqr. 1, H-3525 Miskolc, Hungary 
${ }^{7}$ MTA Centre for Ecological Research, GINOP Sustainable Ecosystems Group, Klebelsberg Kuno str. 3, H-8237 Tihany, Hungary

${ }^{8}$ MTA-DE Lendület Functional and Restoration Ecology Research Group, Egyetem sqr. 1, H4032 Debrecen, Hungary

* corresponding author: istvan.bacsi@gmail.com 


\section{Abstract}

The economic role of certain types of cysts is unquestionable, since the production of several valuable biomolecules is connected to the resting stages of algae, including the red ketocarotenoid astaxanthin. It is relatively well known, how adverse environmental conditions induce cyst formation and astaxanthin accumulation. In the contrary, there is very limited information about stressors inhibiting these processes. An undesirable consequence of increasing drug use of the human and veterinary medicine is the appearance of the drugs both in natural and in mains water. Therefore, to study the effects of micro-contaminants, e.g. pharmaceuticals to non-target aquatic organisms is a recent issue both from ecological and economical point of view. In this study, the effects of three non-steroidal anti inflammatory drugs (NSAIDs: diclofenac, diflunisal and mefenamic acid) on growth, cyst formation and astaxanthin accumulation of the flagellated green alga Haematococcus pluvialis were investigated. All three drugs inhibited growth, inhibition ranged from 29 to $81 \%$ on the basis of vegetative cell numbers on the $14^{\text {th }}$ day of the experiments. Higher concentrations of the drugs led to higher proportion of cysts, which exceeded $60 \%$ of total cell number to the $14^{\text {th }}$ day in diclofenac and diflunisal treatments. On the contrary, astaxanthin contents of treated cultures were lower with the increasing drug concentration, the pigment was undetectable in the presence of 0.075 and $0.05 \mathrm{mg} \mathrm{ml}^{-1}$ diclofenac. Results of carotenoid and chlorophyll content analysis suggest more specific processes behind the observed phenomena than membrane damage. Furthermore, the different phenomena or different extents of the same phenomena suggest that NSAIDs with diverse chemical structures may have different target points in physiological processes. Our results clearly show that NSAIDs could have much wider effective spectra than expected, long-term effects on microalgae might have unexpected ecological or economical consequences due to continuous exposure to these chemicals. 
Keywords: cyst formation, astaxanthin, diclofenac, diflunisal, mefenamic-acid

\section{Introduction}

The presence of a long-lived resting stage (cyst) is a common feature in the case of many planktonic organisms, different algae groups among them (e.g. chrysophytes, diatoms, dinoflagellates and green algae). The economic role of certain types of cysts is unquestionable, since the production of several valuable biomolecules is connected to the resting stages of different algae $[1,2]$. Astaxanthin, the red ketocarotenoid is one of the highvalue microalgal products of the future, mainly because it has higher antioxidant activity than most of the known hydrophobic antioxidants [3]. This pigment has important applications in food and foraging industry, in cosmetics and even in pharmaceutical industry [4]. Although astaxanthin is produced by several organisms (bacteria, yeasts, microalgae, plants; [4]), astaxanthin accumulation of the unicellular freshwater microalga Haematococcus pluvialis exceeds any other known sources [5].

The life cycle of $H$. pluvialis is comprehensively reviewed by Shah et al. [4]. Briefly, the flagellated fast-dividing vegetative cells start losing flagella and expand their cell size under unfavorable environmental or culture conditions, developing into non-motile spherical palmella stage and becoming resting cells [4,6]. Palmella transform into non-dividing aplanospores (cysts) under continued environmental stress (i.e., nutrient deprivation, high light irradiance, high salinity), which accumulate astaxanthin [4]. Some strains are capable to accumulate astaxanthin in the flagellated vegetative stage (without cyst formation; [7]). Although the exact role of astaxanthin in the defense process of the producer cells is strongly contentious until now, the fact that astaxanthin accumulation excessively increases cell 
tolerance to adverse environmental conditions is generally accepted [8-10]. One main role of astaxanthin is thought to be a sunscreen: absorbtion of excessive light and shielding the vulnerable cell structures from photo-oxidative damage [11-14]. Astaxanthin containing lipid droplets in the cytoplasm are also suggested as protectors of the nucleus and the chloroplast from reactive oxygen species (oxidative stress; [8,15]), although results of physiological studies suggest that protection of the cell from reactive oxygen species is mainly performed by the "classic" antioxidant enzymes (catalase, peroxidase and superoxide dismutase); at least at the initial phase of stress-induced astaxanthin accumulation [16]. It is expected, that antioxidative role of astaxanthin could be significant in the lipid droplets, where astaxanthin protects unsaturated fatty acids from oxidation [17]. It is also suggested, that astaxanthin synthesis itself serves as protection system against reactive oxygen species, since the transformation of $\beta$-carotene to astaxanthin consumes oxygen and the biosynthesis of astaxanthin and fatty acids (astaxanthin esthers) provides a potent sink for the photosynthetic products that cannot be utilized for cell growth and division under stress conditions [17].

Generally, cyst formation and secondary metabolite accumulation - as it is already discussed above - occurs in microalgal cells under adverse conditions, when cell division and photosynthesis are slowed down (e.g., under excessive irradiance, nutrient deficiency, extreme temperatures, salinity, and their combinations; $[8,14]$. There are many data in the literature, how high light intensity or UV-irradiance [18,19], nitrate limitation [20,21], or increase of $\mathrm{pH}$ [22] induce cyst formation and astaxanthin accumulation. Effects of small organic compounds on these processes also were investigated: addition of organic carbon sources such as acetate or sugars acts as inducer of astaxanthin production [23,24]. Plant hormones associated with stress response mechanisms (e.g. abscisic acid, jasmonic acid, methyl jasmonate gibberellic acid, salicylic acid, or brassinosteroids) also increased astaxanthin accumulation in $H$. pluvialis [25-30]. However, there is very limited information 
about stressors inhibiting astaxanthin production. It is known that astaxanthin content decreased at high salinity (1-2\%; [22] Sarada et al. 2002), but there are almost no data (at least to our knowledge) how certain micro-contaminants (potentially occurring both in nature and in artificial cultivating systems, especially in open ponds) affect the cyst formation and valuable product accumulation.

The non-steroidal anti-inflammatory drugs (NSAIDs) can be ranked among the most common analgesic products in the world [31]. As a consequence of increasing drug consumption, these drugs appear with increasing frequency in the environment due to their partial metabolization in human and animal body and to the not fully efficient wastewater treatment methods [3234]. Appearance of NSAIDs can be expected even in piped water, although data evince very low concentrations [34]. It is known that these organic micro-contaminants can act as stressors among aerobic photosynthetic microorganisms (cyanobacteria and eukaryotic algae), causing growth inhibition [35-43], or structural changes of natural assemblages $[42,44,45]$. According to the results of our previous work, $H$. pluvialis showed a moderate sensitivity to NSAIDs among eukaryotic algae [42]. Based on our previous data concerning eukaryotic algal assemblages and isolated laboratory strains [42], a more detailed analysis of the toxicity of diclofenac, diflunisal and mefenamic acid was aimed in this study to gain a better understanding between micro-contaminants (NSAIDs) and growth, cyst formation and storage accumulation of a model organism with high economical importance. Our hypotheses were the followings:

- Since concentrations of $0.1 \mathrm{mg} \mathrm{ml}^{-1}$ of the drugs caused serious growth inhibition [42], we assumed that these drugs could be toxic already at lower concentrations.

- We hypothesized that NSAIDs as stress factors may induce morphological changes of flagellated vegetative cells, at least in a part of the exposition time. 
- We assumed that NSAIDs as stress factors may cause changes in pigment composition of $H$. pluvialis cells.

\section{Materials and Methods}

\subsection{The studied NSAIDs}

Diclofenac (Dic), 2-(2,6-dichloranilino)phenylacetic acid belongs to the family of arylalkanoic acids. The molecule contains a chlorinated aromatic group (xenobiotic structure), so its environmental degradation is presumably slow or incomplete [46-50]. It has the classic triple effects of the NSAIDs, such as anti-inflammatory, analgesic and antipyretic effects. Dic inhibits COX-2 more strongly than COX-1. Dic is largely excreted with bile and faeces [51]. Diflunisal (Dif), 5-(2,4-difluorophenyl)salicylic acid belongs to the family of salicylic acid derivatives. It has a fluoro-phenyl structure (xenobiotic structure), suggesting slow or incomplete environmental degradation [50]. Dif effectively reduces pain, swelling and joint stiffness caused by arthritis. In addition, it also has antipyretic effects [52].

Mefenamic acid (Mef), 2-[(2,3-dimetylphenyl)amino]-benzoic acid belongs to the family of antranylic acid derivatives. The molecule has a biphenyl-amine structure (xenobiotic structure), which likely makes its environmental degradation slow or incomplete [53]. Mef is mainly used to treat mild to moderate pain and acute inflammatory diseases [54].

2.2. Algal strain, culturing conditions and experimental setup

Monoalgal cultures of the cosmopolitan flagellated green alga Haematococcus pluvialis are maintained in Optimized Haematococcus Medium (OHM) [55] at $24^{\circ} \mathrm{C}$, under $14 \mathrm{~h}$ light ( 80 
$\mu \mathrm{mol} \mathrm{m} \mathrm{m}^{-2} \mathrm{~s}^{-1}$ fluorescent light) $-10 \mathrm{~h}$ dark cycles in the algal culture collection of the Department of Hydrobiology, University of Debrecen (ACCDH-UD1205).

The experiments were carried out in triplicates, in standing cultures in $100 \mathrm{ml}$ Erlenmeyer flasks with a final volume of $50 \mathrm{ml}$, under $14 \mathrm{~h}$ light $-10 \mathrm{~h}$ dark cycles, at $24^{\circ} \mathrm{C}$. The cultures were hand-shaken daily. Dic, Dif and Mef NSAIDs were applied in $0.025 ; 0.05 ; 0.075$ and 0.1 $\mathrm{mg} \mathrm{ml}^{-1}$ concentration during the treatments. The drugs were dissolved in $10 \mathrm{~g} \mathrm{l}^{-1}$ sodiumcarbonate buffer. Control cultures were prepared without the addition of NSAID solutions. Cultures containing sodium-carbonate buffer without NSAIDs were also applied to check the possible effects of the buffer used for the dissolution of the drugs. To prove the inducible astaxanthin production ability of the used $H$. pluvialis strain, induced cultures were also evaluated. Astaxanthin production was induced by adding $\mathrm{H}_{2} \mathrm{O}_{2}$ and sodium-acetate in final concentrations of 0.01 and $45 \mathrm{mM}$, respectively [23].

2.3. Measuring the growth and morphological changes of the cultures

Growth of the control and treated cultures was followed by counting cell numbers (vegetative cells and cysts separately) at every $48 \mathrm{~h}$ for 14 days. It has to be emphasized that all nonmotile cell types (from the green palmella stage to the red mature aplanospores) were considered as cysts in this study. Cell numbers were counted from $10 \mu 1$ samples in a Bürker chamber on $400 \times$ magnification using an Olympus BX50F-3 fluorescent microscope. To give $\mathrm{EC}_{50}$ values to a certain exposition time (96 hours, 7 or 14 days) for all three NSAIDs, the extents of growth inhibitions ( $\%$, considered control or buffer as $100 \%$ on the given day) were plotted as functions of NSAID concentrations and trend lines were fitted, quadratic regressions showed the best fit $\left(\mathrm{R}^{2}\right.$ values ranged from 0.8872 to 0.9992$)$. The concentrations causing 50\% inhibition were calculated from the equations of the trend lines. 
Since carotenoid production (reddish pigmentation) was not observed in NSAID treated cultures, and the proportion of reddening cysts was under $1 \%$ in control cultures on the $14^{\text {th }}$ day of the experiments, the exposition was continued for further two weeks. All detectable cell types (named as green vegetative cells - GV; green-red vegetative cells - GRV; green cysts - GC; green-red cysts - GRC and red cysts - RC) were counted separately on every week, proportion of them were given in percentage, considering total number of cells counted on a given day as $100 \%$.

\subsection{Qualitative characterization of carotenoid profile of mature cysts}

For qualitative characterisation of carotenoid profile of mature cysts, 4 liters of three-monthold culture of $H$. pluvialis (containing red mature cysts above $95 \%$ ) was centrifuged (Beckman Avanti J-25 centrifuge, $6000 \times g, 10 \mathrm{~min}$ ), supernatant was removed and the pellet was lyophilized (Christ Alpha 1-2 LD plus) and stored at $-20^{\circ} \mathrm{C}$ until further processing.

The freeze-dried sample $(0.5 \mathrm{~g})$ was sonicated in $15 \mathrm{ml}$ methanol : acetone $3: 7 \mathrm{v} / \mathrm{v} \%$ mixture for 5 minutes, and it was let to stand for an hour. After decantation the same extraction procedure was repeated for four times. The extracts were combined and the solvent was evaporated. The crude extract was subjected to HPLC-DAD investigation.

The HPLC analyses were performed with a Dionex Ultimate 3000 HPLC System with Chromeleon 6.8 software. Chromatograms were developed on a $250 \times 4.6 \mathrm{~mm}$ stainless steel $\mathrm{YMC} \mathrm{C}_{30} 3 \mu \mathrm{m}$ endcapped column, with $1.00 \mathrm{ml} / \mathrm{min}$ flow rate, at $22{ }^{\circ} \mathrm{C}$. Eluents were (A) methanol : tert-buthyl methyl ether : water $81: 15: 4 \mathrm{v} / \mathrm{v} \%$, and (B) methanol : tert-buthyl methyl ether : water 6:90:4 v/v\%. The gradient program was the following: 0-45 min from $100 \%$ A to $100 \%$ B (in linear steps). The chromatograms were detected at $450 \mathrm{~nm}$. 
Carotenoids were identified on the basis of their UV-VIS spectra, retention times in HPLC [56], and co-chromatography with authentic samples from our collection.

2.5. Instrumental analysis of pigment content changes

On the $28^{\text {th }}$ day of the exposition, cultures were collected by centrifugation (Beckman Avanti $\mathrm{J}-25$ centrifuge, $6000 \times \mathrm{g}, 10 \mathrm{~min}$ ), supernatants were removed and pellets were freeze dried (Christ Alpha 1-2 LD plus lyophilizer) stored at $-20^{\circ} \mathrm{C}$ until further processing. Pellets were resuspended in $2 \mathrm{ml}$ of dimethyl sulfoxide (DMSO) and extracted for $30 \mathrm{~min}$ at $24^{\circ} \mathrm{C}$ in the dark [57]. After the extraction period, samples were centrifuged $\left(16,200 \times \mathrm{g}, 5 \mathrm{~min}, 24{ }^{\circ} \mathrm{C}\right.$, Heraeus Fresco 17 centrifuge), and supernatants were removed. The pellets were resuspended in $2 \mathrm{ml}$ fresh DMSO, and the extraction was repeated, altogether 4 extraction cycles were implemented. Spectra of all extracts were recorded (350-700 nm, Hach Lange DR 6000 UV/VIS spectrophotometer), pigment contents were identified according to the following equations:

Chlorophyll-a $=12.47 \mathrm{~A}_{660.6}-3.62 \mathrm{~A}_{649.1}$

Chlorophyll-b=25.06 $\mathrm{A}_{649.1}-6.5 \mathrm{~A}_{660.6}$

Carotenoids $=\left(1000 \mathrm{~A}_{480}-1.29 \mathrm{Chl}_{\mathrm{a}}-53.78 \mathrm{Chl}_{\mathrm{b}}\right) / 220$

where $\mathrm{A}_{660.6} ; \mathrm{A}_{649.1}$ and $\mathrm{A}_{480}$ are absorbance at 660.6, 649.1 and $480 \mathrm{~nm} ; \mathrm{Chl}_{\mathrm{a}}$ is the concentration of chlorophyll-a and $\mathrm{Ch}_{\mathrm{b}}$ is the concentration of chlorophyll-b [58-60]. Finally, pigment contents were calculated to unit of dry mass and given as $\mu \mathrm{g} \mathrm{mg}^{-1}$.

The DMSO extracts of the 28-day-old biomasses were used for further analysis of primary carotenoids. The extracts were treated according to the method described by Du et al. [61] with modifications: $375 \mu 1$ diethyl-ether and $375 \mu$ laliquots of the samples (DMSO extracts) were added to $625 \mu \mathrm{l}$ saturated sodium-chloride solution. The mixtures were vigorously 
stirred and then centrifuged (16 $200 \times \mathrm{g}, 5 \mathrm{~min}, 24^{\circ} \mathrm{C}$, Heraeus Fresco 17 microcentrifuge). After centrifugation, $100 \mu 1$ of hexane was added to each samples, the mixtures were stirred and centrifuged again. Aliquots of $300 \mu 1$ of the upper DMSO-free diethyl ether-hexane phases were transferred to new Eppendorf tubes, they were evaporated to dryness in vacuum centrifuge (Christ Rotational-Vacuum-Concentrator SpeedDry 2-25 CDplus Package) and the pellets were extracted by a known volume of $80 \%$ acetone alkalized with ammonia solution $(0,3 \% \mathrm{v} / \mathrm{v})$ and centrifuged, the extraction was repeated twice. Primary carotenoids in the pooled extracts were measured by reversed-phase HPLC procedure suggested by Britton and Young [62] after modification of gradient elution for accurate quantitative separation of minor components. [63].

\subsection{Thin layer chromatography}

The DMSO extracts of the 28-day-old biomasses were used for thin layer chromatographic analysis. The extracts were treated also based on the method described by Du et al. [61] with modifications: $375 \mu 1$ ethyl-acetate and $375 \mu 1$ samples (DMSO extracts) were added to 625 $\mu 1$ saturated sodium-chloride solution. The mixtures were rigorously stirred and than centrifuged $\left(16200 \times \mathrm{g}, 5 \mathrm{~min}, 24^{\circ} \mathrm{C}\right.$, Heraeus Fresco 17 microcentrifuge). Aliquots of $20 \mu \mathrm{l}$ of the upper DMSO-free ethyl-acetate phases were subjected to silica gel $\mathrm{GF}_{254}$. For astaxanthin standard preparation $1.0 \mathrm{mg}$ solid astaxanthin was dissolved in $2.0 \mathrm{ml}$ DMSO. The DMSO solvent was treated as the samples and an aliquot of $10 \mu 1$ was subjected to the TLC plate. Running phase was petroleum ether : acetone $4: 1 \mathrm{v} / \mathrm{v}$, solvent front was $4.0 \mathrm{~cm}$. The plates were photographed and the images were analyzed by CpAtlas 2.0. The proportions of the different pigments were given as percentage of total peak area. 


\subsection{Statistical analyses}

All experiments were done in triplicate. Analysis of covariance (one way ANCOVA; $[64,65]$ ) was used to show differences among the tendencies of cell number changes. The results of spectrophotometric analysis and thin layer chromatography were compared by analysis of variance (one way ANOVA) with Tukey's post-hoc test as multiple comparison test. For statistical analyses the PAST software was used [65].

\section{Results and discussion}

3.1. Growth and morphological changes of the cultures

The buffer used for the dissolution of the NSAIDs slightly inhibited the growth of the green alga Haematococcus pluvialis compared to control, but this inhibition was non-significant, cyst number changes in buffer treated cultures also did not differ significantly from control (Fig. 1). In contrast, the growth was significantly inhibited in all NSAID treated cultures compared to control and buffer treated cultures (Fig. 1). The growth of the vegetative cells in culture treated with 0.075 and $0.1 \mathrm{mg} \mathrm{ml}^{-1}$ Dic was significantly inhibited compared also to the two other Dic concentrations $(p<0.05$; Fig. 1a). The number of cysts increased significantly $(\mathrm{p}<0.05)$ in Dic treated cultures compared to control and buffer treated cultures, but cyst number changes of the Dic treatments did not differed significantly from each other (Fig. 1b). The growth of the cultures treated with Dif also differed significantly from that of control and buffer treated cultures (Fig. 1c). The number of cysts increased significantly compared to control and buffer treated cultures only from $0.05 \mathrm{mg} \mathrm{ml}^{-1}$ Dif (Fig. 1d). Growth of vegetative cells in cultures treated with Mef in $0.05-0.075 \mathrm{mg} \mathrm{ml}^{-1}$ concentration differed 
significantly $(\mathrm{p}<0.05)$ both from control, buffer, and $0.025 \mathrm{mg} \mathrm{ml}^{-1}$ concentration, but not from each other. The highest concentration of $\operatorname{Mef}\left(0.1 \mathrm{mg} \mathrm{ml}^{-1}\right)$ led to significantly lower vegetative cell number in comparison with all other treatments (Fig. 1e). Mef did not cause significant cyst number changes compared to control (Fig. 1f).

Comparing the growth of cultures treated with the different NSAIDs in the same concentrations, it can be said that Dic caused significantly $(\mathrm{p}<0.05)$ stronger growth inhibition of vegetative cells than the other two NSAIDs. Number of cyst was significantly higher in Dic treated cultures than in the others, and it increased significantly higher in Dif treatments than in Mef treatments (except at $0.025 \mathrm{mg} \mathrm{ml}^{-1}$ ).

Effective concentrations causing 50\% growth inhibition ( $\mathrm{EC}_{50}$ values) were calculated both on the basis of vegetative cells and total cell number (vegetative cells and cysts together) for the different drugs for different exposition times, considered growth as $100 \%$ in control or in buffer treated culture (Table 1). As it was expected, $\mathrm{EC}_{50}$ values were lower, when growth in control was considered as $100 \%$, and values calculated on the basis of vegetative cells were lower than values calculated on the basis of total cell number. According to the calculated $\mathrm{EC}_{50}$ data, Dic was the most toxic after 4,7 and also 14 days on the basis of vegetative cell numbers (Table 1). However, Dif and Mef were less toxic in the first week, but $\mathrm{EC}_{50}$ values became more similar after 14 days of exposure (Table 1).

Our first hypothesis was that the drugs could be toxic already in lower concentrations than 0.1 $\mathrm{mg} \mathrm{ml}^{-1}$ used in our previous study [42]. The results confirmed this hypothesis, since already $0.025 \mathrm{mg} \mathrm{ml}^{-1} \mathrm{NSAID}$ concentrations inhibited growth significantly.

Dic is one of the most studied NSAID in relation of acute toxicity on eukaryotic algae. Comparing our results with literature data, the used $H$. pluvialis strain was more sensitive to Dic than the closely related Dunaliella tertiolecta [40], or the non-motile green alga Desmodesmus subspicatus [36,37], but showed less sensitivity than an other non-motile green 
alga Pseudokirchneriella subcapitata [35]. $\mathrm{EC}_{50}$ values calculated on the basis of vegetative cell numbers showed that Dic was the most toxic throughout the exposition time.

According to our knowledge, results presented here are the first that show the effect of Dif along concentration gradient on eukaryotic algal growth. Our previous results showed that $H$. pluvialis was more sensitive to $0.1 \mathrm{mg} \mathrm{ml}^{-1}$ Dif than unicellular cyanobacteria (Synechococcus elongatus, Microcystis aeruginosa) or other eukaryotic algae (Cryptomonas ovata; Desmodesmus communis) [42]. Buffer had the strongest effect on $\mathrm{EC}_{50}$ values in the case of Dif, and growth curves also suggested the weaker toxicity of this NSAID, although $\mathrm{EC}_{50}$ values calculated on the basis of vegetative cells, and considered growth in buffer treated cultures as $100 \%$ showed that Dif also had significant toxicity.

Data about the toxicity of Mef on algae are very limited in the literature. We found no data about effects of Mef on algal growth, Patel et al. [66] showed that Mef in a concentration range $0.002 \mathrm{mM}-0.2 \mathrm{mM}\left(\sim 0.0005-0.05 \mathrm{mg} \mathrm{ml}^{-1}\right)$ had a dramatic effect on the distribution of various chemical species in the desmid Micrasterias hardyi. According to our previous results, $H$. pluvialis was more sensitive to $0.1 \mathrm{mg} \mathrm{ml}^{-1}$ Mef than unicellular cyanobacteria (Synechococcus elongatus, Microcystis aeruginosa) or other eukaryotic algae (Cryptomonas ovata; Desmodesmus communis) [42]. $\mathrm{EC}_{50}$ values calculated on the basis of vegetative cell numbers shows that Mef was the less toxic in the first half of the exposition time, but in the contrary, this drug proved to have comparable toxicity to the others after 14 days of exposure. The reason of this phenomenon is that Mef inhibited the growth of vegetative cells as well as cyst formation within the firs two weeks.

As it can be seen from growth data, number of cysts increased also in control culture: a tenfold increase occurred to the $7^{\text {th }}$ day and a further twofold increase of this amount was observed to the $14^{\text {th }}$ day (Fig 1). However, even with these increases, proportion of cysts was only $24 \%$ of total cell number on the $14^{\text {th }}$ day, reddish pigmentation appeared only on the $7^{\text {th }}$ 
day (Fig. A1a). Cell type changes occurred very similarly in the buffer treated culture (Fig. A1b). Almost all cells turned into cysts in induced culture to the $7^{\text {th }}$ day, but reddish pigmentation (green-red cysts and red cysts; GRC, RC) appeared only in low proportion $(2.4 \%)$ at this time. This low amount of GRC and GC increased during the extended exposition, proportion of GRC was above $70 \%$, and RC exceeded $9 \%$ in induced cultures on the $28^{\text {th }}$ day (Fig. A1c). Proportion of cysts increased, but they mostly remained green in NSAID treated cultures throughout the extended experiments (Fig. A2-A4). Reddish pigmentation appeared only from the $14^{\text {th }}$ day, proportion of GRC decreased with increasing Dif concentration, and almost no reddish pigmentation was detected in Dic and Mef treated cultures (Fig. A2-A4).

We hypothesized that NSAIDs as stress factors, may induce morphological changes of flagellated vegetative cells. This hypothesis was confirmed: number of non-motile cells significantly increased to the $14^{\text {th }}$ day in Dic and Dif treated cultures, and almost all cells turned into cysts to the $21^{\text {st }}$ or $28^{\text {th }}$ day also in Mef treated cultures. It has to be emphasized that the formed non-motile cells remained green, especially in NSAID treated cultures, so according to Shah et al. [4], they represented the so-called pallmella stage with thick cell wall and highly developed chloroplasts located at the periphery of the cells. Induction by addition of hydrogen peroxide and acetate proved the inducible cyst formation and carotenoid accumulation of the studied $H$. pluvialis strain, so NSAIDs seem to initiate morphological changes but inhibit the full proliferation of mature cysts, mainly carotenoid accumulation (see section 3.3.).

\subsection{Qualitative characterisation of mature cyst's pigment composition}


Qualitative characterization of carotenoid profile of mature cysts was carried out from the dried biomass of three-month-old culture containing red cysts above 95\%. The analysis showed that the main red carotenoid in the mature cyst of the investigated $H$. pluvialis strain was astaxanthin, which was present mainly as monoesthers $(38 \%$ of all separated peaks on the basis of peak area, Fig 2, Table 2). Astaxanthin was also present as diesthers (10\%), and as free astaxanthin $(2 \%$; Fig 2 , Table 2$)$. Other pigments in relevant amounts were $\beta$-carotene, lutein, canthaxanthin and echinenone $(17 ; \sim 7 ; \sim 5$ and $\sim 3 \%$ of all separated peaks on the basis of peak area, respectively) and (9Z)- $\beta$-carotene was also detectable (1.2\%; Fig 2; Table 2).

According to these results, it can be stated that the studied $H$. pluvialis strain accumulates astaxanthin mainly as mono- and diesthers. Induction by addition of hydrogen peroxide and acetate lead to the high proportion of green-red cysts (so called intermediate cell stage in Shah et al. [4]) within 14 days. Our strain can be characterized similarly to other strains described in the literature NIES-144 [23,25,67-70]; UTEX\#2505 [71]; Strain 712 [72], although formation of completely mature cysts (red aplanospores) required more time for the investigated $H$. pluvialis strain among the applied circumstances.

\subsection{Analysis of pigment content}

Spectrophotometric analysis of biomasses collected on the $28^{\text {th }}$ day of the extended experiment showed that old cysts and induced cultures contained significantly $(p<0.001)$ higher amount of carotenoids than control (Fig. 3). Carotenoid content in treated cultures decreased with the increase of drug concentration, cultures treated with $0.05-0.1 \mu \mathrm{g} \mathrm{ml} \mathrm{l}^{-1}$ NSAID contained significantly $(\mathrm{p}<0.05)$ lower amount of carotenoids than control (Fig. 3). Chlorophyll-a and -b (Chl-a, -b) content of the cultures showed a different picture: amounts of Chl-a and -b were similar in control, induced, and buffer treated cultures and in old cysts, 
while Dic and Mef treated cultures could be characterized with increasing levels of both Chl$\mathrm{a}$ and $-\mathrm{b}$ with the increasing NSAID concentrations (Fig. 3). In contrast, Chl content of Dif treated cultures did not differ significantly from that of control (Fig. 3). Further analysis of carotenoid composition showed, that the main primary carotenoids of the investigated $H$. pluvialis strain are lutein, $\beta$-carotene, violaxanthin, neoxanthin and zeaxanthin (data not shown). These findings are in accordance with literature data, [73] also found these primary carotenoid pigments mainly characteristic to $H$. pluvialis. Amounts of the two main primary carotenoids, lutein and $\beta$-carotene were lower in cultures, which accumulated astaxanthin (old cysts, induced, control and buffer treated cultures), and were higher in cultures treated with NSAIDs (Table A1).

Thin layer chromatographic characteristics of free astaxanthin standard were well comparable with literature data: $\mathrm{Rf}$ value in this study was 0.2 ( $\mathrm{Rf}$ reported by $\mathrm{Du}$ et al. [61]: 0.21). Altogether eight peaks could be separated during the analysis of the TLC plate. On the basis of color, location on the thin layer, and qualitative analysis of the carotenoid content of the mature cysts (see section 3.2.), peaks 1-3 were identified as chlorophylls and free astaxanthin (the latter could not be clearly separated by CpAtlas), peaks 4-7 were identified as asthaxanthin mono- and diesthers and peak 8 was identified as $\beta$-carotene (Fig. 4a). Compared to control and buffer treatment, the proportion of astaxanthin esters significantly decreased with the increasing drug concentration in all cases of NSAIDs ( $p<0.001$; Fig. 4b). The decrease was the most pronounced in the case of Dic, since at 0.075 and $0.1 \mathrm{mg} \mathrm{ml}^{-1}$ concentrations no astaxanthin were detected (Fig. 4b). Dif caused the lowest decrease in astaxanthin content (Fig. 4b). Mef caused significant decrease in astaxanthin content from $0.05 \mathrm{mg} \mathrm{ml}^{-1}$ concentration compared to control and buffer treatment, but red pigments were present even at the highest Mef concentration (Fig. 4b). 
Instrumental and TLC analyses both proved that NSAIDs inhibit secondary carotenoid accumulation. TLC analysis also proved that pigment composition of three-month-old red mature cysts and induced cultures are very similar. On the bases of these results it can be concluded that our third hypothesis, according to which NSAIDs as stress factors may cause changes in pigment composition of $H$. pluvialis cells, was also proved. Presence of NSAIDs (especially Dic and Mef) led to the lack of carotenoid accumulation, mainly the synthesis of astaxanthin was inhibited. According to our knowledge, these are the first results of the effects of NSAIDs on resting stage and storage accumulation in algal life cycle. In the present state of knowledge, NSAID toxicity on microorganisms could be connected to their membrane damaging effects due to weak water solubility and related lipophility $[34,45,74]$. One possible explanation to the observed effects could be that the first part of astaxanthin synthesis (production of $\beta$-carotene from isopentenylpyrophosphate precursors) is linked to chloroplast membranes [10], so membrane damage could be a reason of low astaxanthin content in NSAID treated cultures. However, higher chlorophyll, lutein and $\beta$-carotene levels in NSAID treated cultures do not support exclusively this explanation.

It is well known that NSAIDs reversibly or irreversibly inhibit the operation of one or both isoforms of cyclooxygenase enzymes (COX-1, COX-2) in target organisms (in animals and humans) [75]. The conversion of $\beta$-carotene to astaxanthin in H. pluvialis (and in other producers) requires introduction of two hydroxyl groups (in the positions 3 and 3') and two keto-groups (in the positions 4 and 4'; Table 2) [17]. Lemoine and Schoefs [10] suggest that the metabolic pathway to astaxanthin is via conversion of $\beta$-carotene to echinenone and than to canthaxanthin by $4,4^{\prime}$-ketolase (carotenoid 4,4'-oxygenase), followed by hydroxylation to adonirubin and finally to astaxanthin by $3,3^{\prime}$ '-hydroxylase ( $\beta$-carotene $3,3^{\prime}$-monooxygenase) [10]. Interaction of NSAIDs with these involved oxygenases could be an other possible explanation for the lack of astaxanthin accumulation. The two main primary carotenoids, 
lutein and $\beta$-carotene biosynthetically originate from lycopene via $\delta$ - and $\alpha$-carotene for the former and via $\gamma$-carotene for the latter [4]. $\beta$-carotene is a precursor for astaxanthin synthesis $[4 ; 10]$. In the case of astaxanthin accumulation, the pathway must be shifted towards $\beta$ carotene synthesis, which explains the lower amount of lutein in astaxanthin accumulating cultures. The further metabolism of $\beta$-carotene to astaxanthin explains the lower amounts of this pigment in the same cultures. As it was already discussed above, astaxanthin accumulation may provide a potent sink for the products of photosynthesis that cannot be utilized for cell growth and division under stress [17]. If astaxanthin synthesis is blocked, alternative pathways or accumulation of precursors can come to view: shifting of lycopene metabolism toward lutein synthesis results increased lutein level, and/or may cause the accumulation of $\beta$-carotene. Higher amounts of lutein and $\beta$-carotene in NSAID treated cultures can be explained with these processes. However, exact explanation absolutely requires further studies.

The elevated chlorophyll content in NSAID treated cultures at the end of the extended exposure (at the $28^{\text {th }}$ day) was an unexpected phenomenon. Chlorophyll content of microalgal cells could be increased mainly by low light intensity [76-79], and can be interpreted as shade-adaptation [80]. Although cysts tend to sink to the bottom, which could lead to reduced light availability, the lack of increase in chlorophyll content of all other cultures than NSAID treated ones excludes likely this explanation. Another, but rather speculative explanation of chlorophyll content increases in NSAID treated cultures could be the following: As it was mentioned above, astaxanthin accumulation may provide a potent sink for the products of photosynthesis that cannot be utilized for cell growth and division under stress (caused by the presence of NSAIDs in the present case). Since astaxanthin production is blocked in the presence of NSAIDs, chlorophyll accumulation may occur as a substitutional process beside the remaining primary carotenoid content. Although according to literature data 
decomposition of photosynthetic apparatus occurs in parallel with cyst formation, non-motile green coccoid cells contain highly developed chloroplasts [4] as it is discussed above (section 3.1). Increased amount of chlorophylls in NSAID treated cultures also suggests some more specific effects of these drugs than an average membrane damaging effect, since many enzymes involved in chlorophyll synthesis are also bound to in chloroplast membranes [81]. Exact explanation of these phenomena definitely requires further investigations.

\section{Conclusions}

Our study presents new data about the effects of NSAIDs to Haematococcus pluvialis as a representative of cyst forming eukaryotic algae with connected economic importance. All three tested NSAID with different, hardly degradable xenobiotic structures caused significant growth inhibition. In-time decreasing $\mathrm{EC}_{50}$ values suggest that long-term effects might also have unexpected ecological or economical consequences due to continuous exposure to chemicals. All three tested NSAIDs initiated morphological changes (cyst formation): number of palmella stage (green cysts) exceeded $80 \%$ during all three treatments, but inhibited its completion (formation of mature cysts) and asthaxanthin accumulation: number of intermediate stage (green-red cysts) decreased from the average $6.5 \%$ to $1.4 \%$ and under the limit of detection with the increasing concentration of diflunisal, diclofenac and mefenamic acid, respectively. Results of pigment analysis suggest more specific processes behind the observed phenomena than membrane damage. Furthermore, the different phenomena or different extents of the same phenomena suggest that NSAIDs with diverse chemical structures may have different target points in physiological processes. These results prove that adverse effects of drugs and drug derivatives can be expected not only on humans or animals, but also on algae, meaning not only ecologically but economically relevant phenomena. 


\section{Acknowledgements}

This work was supported by the National Research, Development and Innovation Office (NKFIH) GINOP-2.3.2-15-2016-00019; PD 112374 (S. Gonda), K 119647 (G. Vasas), and K 115931 (J. Deli) and partially supported by the European Union and the European Social Fund through project EFOP-3.6.1-16-2016-00022.

\section{Author Contributions}

István Bácsi: conception and design of the study, acquisition of data, analysis and interpretation of data, and drafting the article.

József Deli: High Performance Liquid Chromatography analysis, drafting the concerning Materials and Methods section and figure legend.

Sándor Gonda: Thin Layer Chromatography design, critical revision of the article for important intellectual content.

Ilona Mészáros: HPLC analysis of primary carotenoids, acquisition and analysis of data.

Gréta Veréb: Implementation of toxicology tests with diflunisal, acquisition and analysis of data.

Dalma Dobronoki: Implementation of toxicology tests with diclofenac, acquisition and analysis of data.

Sándor Alex Nagy: Additional financial support, provision of study materials.

Viktória B-Béres: Implementation of toxicology tests with mefenamic-acid, acquisition and analysis of data. 
Gábor Vasas: conception and design of the study, critical revision of the article for important intellectual content, final approval of the article.

\section{Conflict of Interest}

The authors declare that there is no conflict of interest.

\section{Statement of Informed Consent, Human/Animal Rights}

No conflicts, informed consent, human or animal rights applicable.

\section{References}

[1] K.A. Minhas, P. Hodgson, C.J. Barrow, A. Adholeya, A review on the assessment of stress conditions for simultaneous production of microalgal lipids and carotenoids, Front. Microbiol. 7 (2016) Article 534 1-19. DOI: 10.3389/fmicb.2016.00546

[2] N.F. Santos-Sánchez, R. Valadez-Blanco, B. Hernández-Carlos, A. Torres-Ariño, P.C. Guadarrama-Mendoza, R. Salas-Coronado, Lipids rich in $\omega-3$ polyunsaturated fatty acids from microalgae, Appl. Microbiol. Biotechnol. 100 (2016) 8667-8684. DOI: $10.1007 / \mathrm{s} 00253-016-7818-8$

[3] M. Guerin, M.E. Huntley, M. Olaizola, Haematococcus astaxanthin: applications for human health and nutrition, Trends Biotechnol. 21 (2003) 210-216. DOI: $10.1016 / \mathrm{S} 0167-7799(03) 00078-7$ 
[4] M.M. Shah, Y. Liang, J.J. Cheng, M. Daroch, Astaxanthin-producing green microalga Haematococcus pluvialis: from single cell to high value commercial products, Front. Microbiol. 7 (2016) Article 531 1-28. DOI: 10.3389/fpls.2016.00531

[5] S. Boussiba, B. Wang, J.P. Yuan, A. Zarka, C. Feng, Changes in pigments profile in the green alga Haematococcus pluvialis exposed to environmental stresses, Biotechnol. Lett. 21 (1999) 601-604. DOI: 10.1023/A:1005507514694

[6] C. Hagen, S. Siegmund, W. Braune, Ultrastructural and chemical changes in the cell wall of Haematococcus pluvialis (Volvocales, Chlorophyta) during aplanospore formation, Eur. J. Phycol. 37 (2002) 217-226. DOI: 10.1017/S0967026202003669

[7] B.R. Brinda, R. Sarada, B.S. Kamath, G.A. Ravishankar, Accumulation of astaxanthin in flagellated cells of Haematococcus pluvialis - cultural and regulatory aspects, Curr. Sci. 87 (2004) 1290-1294.

[8] S. Boussiba, Carotenogenesis in the green alga Haematococcus pluvialis: cellular physiology and stress response, Physiol. Plant. 108 (2000) 111-117. DOI: 10.1034/j.1399-3054.2000.108002111.x

[9] B. Wang, A. Zarka, A. Trebst, S. Boussiba, Astaxanthin accumulation in Haematococcus pluvialis (Chlorophyceae) as an active photoprotective process under high irradiance, J. Phycol. 39 (2003) 1116-1124. DOI: 10.1111/j.0022-3646.2003.03-043.x

[10] Y. Lemoine, B. Schoefs, Secondary ketocarotenoid astaxanthin biosynthesis in algae: a multifunctional response to stress, Photosyth. Res. 106 (2010) 155-177. DOI: $10.1007 / \mathrm{s} 11120-010-9583-3$

[11] C. Hagen, W. Braune, L. Björn, Functional aspects of secondary carotenoids in Haematococcus lacustris (Volvocales). III. Action as a "sunshade", J. Phycol. 30 (1994) 241-248. DOI: 10.1111/j.0022-3646.1994.00241.x 
[12] A. Solovchenko, Pigment composition, optical properties, and resistance to photodamage of the microalga Haematococcus pluvialis cultivated under high light, Russ. J. Plant Physiol. 58 (2011) 9-17. DOI: 10.1134/S1021443710061056

[13] D. Han, J. Wang, M. Sommerfeld, Q. Hu, Susceptibility and protective mechanisms of motile and non motile cells of Haematococcus pluvialis (Chlorophyceae) to photooxidative stress, J. Phycol. 48 (2012) 693-705. DOI: 10.1111/j.15298817.2012.01147.x

[14] A. Solovchenko, Physiology and adaptive significance of secondary carotenogenesis in green microalgae, Russ. J. Plant Physiol. 60 (2013) 1-13. DOI: 10.1134/S102144371

[15] C. Hagen, W. Braune, F. Greulich, Functional aspects of secondary carotenoids in Haematococcus lacustris [Girod] Rostafinski (Volvocales) IV. Protection from photodynamic damage, J. Photochem. Photobiol. B 20 (1993) 153-160

[16] S-B. Wang, F. Chen, M. Sommerfeld, Q. Hu, Proteomic analysis of molecular response to oxidative stress by the green alga Haematococcus pluvialis (Chlorophyceae), Planta 220 (2004) 17-29. DOI: 10.1007/s00425-004-1323-5

[17] A. Solovchenko, Recent breakthroughs in the biology of astaxanthin accumulation by microalgal cell, Photosynth. Res. 125 (2015) 437-449. DOI: 10.1007/s11120-015-01563

[18] Y. Li, M. Sommerfeld, F. Chen, Q. Hu, Effect of photon flux densities on regulation of carotenogenesis and cell viability of Haematococcus pluvialis (Chlorophyceae), J. Appl. Phycol. 22 (2010) 253-263. DOI: 10.1007/s10811-009-9453-6

[19] Z. Wu, G. Chen, S. Chong, N. Mak, F. Chen, Y. Jiang, Ultraviolet-B radiation improves astaxanthin accumulation in green microalga Haematococcus pluvialis, Biotchnol. Lett. 32 (2010) 1911-1914. DOI: 10.1007/s10529-010-0371-0 
[20] J. Fábregas, A. Domínguez, A. Maseda, A. Otero, Interactions between irradiance and nutrient availability during astaxanthin accumulation and degradation in Haematococcus pluvialis, Appl. Microbiol. Biot. 61 (2003) 545-551. DOI $10.1007 / \mathrm{s} 00253-002-1204-4$

[21] M. Orosa, D. Franqueira, A. Cid, J. Abalde, Analysis and enhancement of asatxanthin accumulation in Haematococcus pluvialis, Bioresource Technol. 96 (2005) 373-378. DOI: 10.1016/j.biortech.2004.04.006

[22] R. Sarada, U. Tripathi, G.A. Ravishankar, Influence of stress on astaxanthin production in Haematococcus pluvialis grown under different culture conditions, Process Biochem. 37 (2002) 623-627. DOI: 10.1016/S0032-9592(01)00246-1

[23] M. Kobayashi, T. Kakizono, S. Nagai, Enhanced carotenoid biosynthesis by oxidative stress in acetate-induced cyst cells of a green unicellular alga Haematococcus pluvialis, Appl. Environ. Microbiol. 59 (1993) 867-873.

[24] M. Kobayashi, In vivo antioxidant role of astaxanthin under oxidative stress in the green alga Haematococcus pluvialis, Appl. Microbiol. Biotechnol. 54 (2000) 550-555. DOI: $10.1007 / \mathrm{s} 002530000416$

[25] M. Kobayashi, N. Hirai, Y. Kurimura, H. Ohigashi, Y. Tsuji, Abscisic acid-dependent algal morphogenesis in the unicellular green alga Haematococcus pluvialis, Plant Growth Regul. 22 (1997) 79-85. DOI: 10.1023/A:1005862809711

[26] Z. Gao, C. Meng, X. Zhang, D. Xu, X. Miao, Y. Wang, L. Yang, H. Lv, L. Chen, N. Ye, Induction of salicylic acid (SA) on transcriptional expression of eight carotenoid genes and astaxanthin accumulation in Haematococcus pluvialis, Enzyme Microb. Technol. 51 (2012) 225-230. DOI: 10.1016/j.enzmictec.2012.07.001.

[27] Z. Gao, C. Meng, X. Zhang, D. Xu, Y. Zhao, Y. Wang, H. Lv, L. Yang, L. Chen, N. Ye. Differential expression of carotenogenic genes, associated changes on astaxanthin 
production and photosynthesis features induced by JA in H. pluvialis, PLoSONE 7 (2012) c42243. DOI: 10.1371/journal.pone.0042243

[28] Z. Gao, C. Meng, H. Gao, X. Zhang, D. Xu, Y. Su, Y. Wang, Y. Zhao, N. Ye, Analysis of mRNA expression profiles of carotenogenesis and astaxanthin production of Haematococcus pluvialis under exogenous 2,4-epibrassinolide, Biol. Res. 46 (2013), 201-206. DOI: 10.4067/S0716-97602013000200012

[29] Z. Gao, C. Meng, H. Gao, Y. Li, X. Zhang, D. Xu, S. Zhou, B. Liu, Y. Su, N. Ye, Carotenoid genes transcriptional regulation for astaxanthin accumulation in freshwater unicellular alga Haematococcus pluvialis by gibberellin A3 (GA3), Ind. J. Biochem. Biophys. 50 (2013) 548-553.

[30] X. Yu, L. Chen, W. Zhang, Chemicals to enhance microalgal growth and accumulation of high-value bioproducts, Front. Microbiol. 6 (2015) Article 56 1-10.

[31] M.R. Griffin, Pain Relief: How NSAIDs Work, WebMD (2016) accessed 23.08.2016. (http://www.webmd.com/arthritis/features/pain-relief-how-nsaids-work).

[32] V. Koutsouba, T. Heberer, B. Fuhrmann, K. Schmidt-Baumler, D. Tsipi, A. Hiskia, Determination of polar pharmaceuticals in sewage water of Greece by gas chromatography-mass spectrometry, Chemosphere 51 (2003) 69-75. DOI: $10.1016 / \mathrm{S} 0045-6535(02) 00819-6$

[33] P.K. Jjemba, Excretion and ecotoxicity of pharmaceutical and personal care products in the environment, Ecotox. Environ. Safe. 63 (2006) 113-130. DOI: 10.1016/j.ecoenv.2004.11.011

[34] L.H.M.L.M. Santos, A.N. Araújo, A. Fachini, A. Pena, C. Delerue-Matos, M.C.B.S.M. Montenegro, Ecotoxicological aspects related to the presence of pharmaceuticals in the aquatic environment, J. Hazard. Mater. 175 (2010) 45-95. DOI: 10.1016/j.jhazmat.2009.10.100 
[35] B. Ferrari, N. Paxeus, R.L. Giudice, A. Pollio, J. Garric, Ecotoxicological impact of pharmaceuticals found in treated wastewaters: study of carbamazepine, clofibric acid, and diclofenac, Ecotoxicol. Environ. Safe. 55 (2003) 359-370. DOI: 10.1016/S01476513(02)00082-9

[36] M. Cleuvers, Aquatic ecotoxicity of pharmaceuticals including the assessment of combination effects, Toxicol. Lett. 142 (2003) 185-194. DOI: 10.1016/S03784274(03)00068-7

[37] M. Cleuvers, Mixture toxicity of the anti-inflammatory drugs diclofenac, ibuprofen, naproxen, and acetylsalicylic acid, Ecotoxicol. Environ. Safe. 59 (2004) 309-315. DOI: 10.1016/S0147-6513(03)00141-6

[38] F. Pomati, A.G. Netting, D. Calamari, B.A. Neilan, Effects of erythromycin, tetracycline and ibuprofen on the growth of Synechocystis sp. and Lemna minor, Aquat. Toxicol. 67 (2004) 387-396. DOI: 10.1016/j.aquatox.2004.02.001

[39] M. Schmitt-Jansen, P. Bartels, N. Adler, R. Altenburger, Phytotoxicity assessment of diclofenac and its phototransformation products, Anal. Bioanal. Chem. 387 (2007) 1389-1396. DOI: 10.1007/s00216-006-0825-3

[40] M.E. DeLorenzo, J. Fleming, Individual and mixture effects of selected pharmaceuticals and personal care products on the marine phytoplankton species Dunaliella tertiolecta, Arch. Environ. Contam. Toxicol. 54 (2008) 203-210. DOI: 10.1007/s00244-007-9032-2

[41] I. Moro, V. Matozzo, A. Piovan, E. Moschin, F.D. Vecchia, Morpho-physiological effects of ibuprofen on Scenedesmus rubescens, Environ. Toxicol. Phar. 38 (2014) 379387. DOI: 10.1016/j.etap.2014.06.005

[42] I. Bácsi, V. B-Béres, Z. Kókai, S. Gonda, Z. Novák, S.A. Nagy, G. Vasas, Effects of non-steroidal anti-inflammatory drugs on cyanobacteria and algae in laboratory strains 
and in natural algal assemblages, Environ. Pollut. 212 (2016) 508-518. DOI: 10.1016/j.envpol.2016.02.031

[43] E. Geiger, R. Hornek-Gausterer, M.T. Saçan, Single and mixture toxicity of pharmaceuticals and chlorophenols to freshwater algae Chlorella vulgaris, Ecotox. Environ. Safe. 129 (2016) 189-198. DOI: 10.1016/j.ecoenv.2016.03.032

[44] L. Proia, V. Osorio, S. Soley, M. Köck-Schulmeyer, S. Pérez, D. Barceló, A.M. Romaní, S. Sabater, Effects of pesticides and pharmaceuticals on biofilms in a highly impacted river, Environ. Pollut. 178 (2013) 220-228. DOI: 10.1016/j.envpol.2013.02.022

[45] N. Corcoll, V. Acuña, D. Barceló, M. Casellas, H. Guasch, B. Huerta, M. Petrovic, L. Ponsatí, S. Rodríguez-Mozaz, S. Sabater, Pollution-induced community tolerance to non-steroidal anti-inflammatory drugs (NSAIDs) in fluvial biofilm communities affected by WWTP effluents, Chemosphere 112 (2014) 185-193. DOI: 10.1016/j.chemosphere.2014.03.128

[46] C. Zwiener, F.H. Frimmel, Short-term tests with a pilot sewage plant and biofilm reactors for the biological degradation of the pharmaceutical compounds clofibric acid, ibuprofen, and diclofenac, Sci Total Environ, 309 (2003) 201-211. DOI:10.1016/S00489697(03)00002-0

[47] T. Kosjek, E. Heath, S. Pérez, M. Petrović, D. Barceló, Metabolism studies of diclofenac and clofibric acid in activated sludge bioreactors using liquid chromatography with quadrupole - time-of-flight mass spectrometry, J Hydrol, 372 (2009) 109-117. DOI : 10.1016/j.jhydrol.2009.04.006

[48] A. Langenhoff, N. Inderfurth, T. Veuskens, G. Schraa, M. Blokland, K. KujawaRoeleveld, H. Rijnaarts, Microbial Removal of the Pharmaceutical Compounds Ibuprofen and Diclofenac from Wastewater, BioMed Res Int, Article ID 325806, (2013) 1-9. DOI: $10.1155 / 2013 / 325806$ 
[49] A. Kruglova, P. Ahlgren, N. Korhonen, P. Rantanen, A. Mikola, R. Vahala,. Biodegradation of ibuprofen, diclofenac and carbamazepine in nitrifying activated sludge under $12{ }^{\circ} \mathrm{C}$ temperature conditions, Sci Total Environ, 499 (2014) 394-401. DOI: $10.1016 /$ j.scitotenv.2014.08.069.

[50] S. Gonda, A. Kiss-Szikszai, Z. Szücs, B. Balla, G. Vasas, Efficient biotransformation of non-steroid anti-inflammatory drugs by endophytic and epiphytic fungi from dried leaves of a medicinal plant, Plantago lanceolata L, Int Biodeter Biodeg, 108 (2016) 115-121. DOI: 10.1016/j.ibiod.2015.12.018

[51] Z. Fürst, Pharmacology (In Hungarian: Farmakológia) Medicina, (2001) Budapest.

[52] S.S. Adams, Ibuprofen, the propionics and NSAIDs: Personal reflections over four decades, Inflammopharmacology, 7 (1999) 191-197. DOI :10.1007/s10787-999-0002-3

[53] T. Hata, S. Kawai, H. Okamura, T. Nishida, Removal of diclofenac and mefenamic acid by the white rot fungus Phanerochaete sordida YK-624 and identification of their metabolites after fungal transformation, Biodegradation, 21 (2010) 681-689. DOI: $10.1007 / \mathrm{s} 10532-010-9334-3$

[54] T. Pringsheim, W.J. Davenport, D. Dodick,. Acute Treatment and Prevention of Menstrually Related Migraine Headache: Evidence-Based Review, Neurology 70 (2008) 1555-1563. DOI:10.1212/01.wnl.0000310638.54698.36

[55] J. Fábregas, A. Domínguez, M. Regueiro, A. Maseda, A. Otero, Optimization of culture medium for the continuous cultivation of the microalga Haematococcus pluvialis, Applied Microbiology Biotecnology 53 (2000) 530-535. DOI: 10.1007/s002530051652

[56] E. Turcsi, V. Nagy, J. Deli, Study on the elution order of carotenoids on endcapped $\mathrm{C}_{18}$ and $\mathrm{C}_{30}$ reverse silica stationary phase. A review of the database, J. Food Comp. Anal. 47 (2016) 101-112. DOI: 10.1016/j.jfca.2016.01.005 
[57] Technical Report TR.1002.001, Analysis of Total Astaxanthin in algae meal prepared from Haematococcus pluvialis, Aquasearch, Kona, Hawaii, 1999.

[58] H.K. Lichtenthaler A.R. Wellburn, Determinations of total carotenoids and chlorophylls $\mathrm{a}$ and $\mathrm{b}$ of leaf extracts in different solvents, Biochem. Soc. Trans. 11 (1983) 591-592. DOI: $10.1042 /$ bst0110591

[59] H.K. Lichtenthaler, Chlorophylls and carotenoids: pigments of photosynthetic membranes, Method Enzymol. 148 (1987) 350-382. DOI: 10.1016/00766879(87)48036-1

[60] R.J. Porra, The chequered history of the development and use of simultaneous equations for the accurate determination of chlorophylls a and b, Photosynth. Res. 73 (2002) 149156. DOI: $10.1023 / \mathrm{A}: 1020470224740$

[61] X. Du, C. Dong, K. Wang, Z. Jiang, Y. Chen, Y. Yang, F. Chen, H. Ni, Separation and purification of astaxanthin from Phaffia rhodozyma by preparative high-speed countercurrent chromatography, Journal of Chromatography B, 1029-1030 (2016) 191-197. DOI: $10.1016 /$ j.jchromb.2016.06.042

[62] G. Britton, A.J. Young Methods for the isolation and analysis of carotenoids. In: Young, A. J. and Britton, G. (eds) Carotenoids in Photosynthesis. Chapman \& Hall, London, 1993, pp. 409-459. DOI: 10.1007/978-94-011-2124-8

[63] R.V. Tóth, I. Mészáros, S. Veres, J. Nagy, Effects of the available nitrogen on the photosynthetic activity and xanthophyll cycle pool of maize in field, J. Plant Physiol, 159 (2002) 627-634. DOI: 10.1078/0176-1617-0640

[64] J.H. Zar, Biostatistical Analysis, third ed., Prentice-Hall International, New Jersey, 1996.

[65] O. Hammer, D.A.T. Harper, P.D. Ryan, PAST: paleontological statistics software package for education and data analysis, Palaeontologia Electronica, 4 (1) (2001) Unpaginated. 
[66] S.A. Patel, F. Currie, N. Thakker, R. Goodacre, Spatial metabolic fingerprinting using FT-IR spectroscopy: investigating abiotic stresses on Micrasterias hardyi, Analyst 133 (2008) 1707-1713. DOI: 10.1039/b809441a

[67] M. Kobayashi, T. Kakizono, N. Nishio, S. Nagai, Y. Kurimura, Y. Tsuji, Antioxidant role of astaxanthin in the green alga Haematococcus pluvialis, Appl. Microbiol. Biotechnol. 48 (1997) 351-356. DOI: 10.1007/s002530051

[68] M. Kobayashi, Y. Todoroki, N. Hirai, Y. Korimura, H. Ohigashi, Y. Tsuji, Biological activities of abscisic acid analogs in the morphological change of the green alga Haematococcus pluvialis, J. Fermentation Bioeng. 85 (1998) 529-531. DOI: $10.1016 / \mathrm{S} 0922-338 \mathrm{X}(98) 80079-7$

[69] M. Kobayashi, T. Katsuragi, Y. Tani, Enlarged and astaxanthin-accumulating cyst cells of the green alga Haematococcus pluvialis, J. Biosci. Bioeng. 92 (2001) 565-568. DOI: 10.1016/S1389-1723(01)80317-0

[70] M. Kobayashi, Astaxanthin biosynthesis enhanced by reactive oxigen species in the green alga Haematococcus pluvialis, Biotech. Bioprocess Eng 8 (2003) 322-330. DOI: 10.1007/BF02949275

[71] C. Lee, Y-E. Choi, Y-S. Yun, A strategy for promoting astaxanthin accumulation in Haematococcus pluvialis by 1-aminocyclopropane-1-carboxylic acid application, J. Biotechnol. 236 (2016) 120-127. DOI: 10.1016/j.jbiotec.2016.08.012

[72] N. Wang, B. Guan, Q. Kong, H. Sun, Z. Geng, L. Duan, Enhancement of astaxanthin production from Haematococcus pluvialis mutants by three-stage mutagenesis breeding, J. Biotechnol. 236 (2016) 71-77. DOI: 10.1016/j.jbiotec.2016.08.009

[73] C.B. Grewe, C. Griehl, The carotenoid astaxanthin from Haematococcus pluvialis in: C. Posten and C. Walter (eds) Microalgal Biotechnology: Integration and Economy, DeGruyter, Berlin, Boston, MA, 129-144. DOI: 10.1515/9783110298321.129 
[74] B.I. Escher, N. Bramaz, R.I.L. Eggen, M. Richter, In vitro assessment of modes of toxic action of pharmaceuticals in aquatic life, Environ. Sci. Technol. 39 (2005) 3090-3100. DOI: $10.1021 / \mathrm{es} 048590 \mathrm{e}$

[75] J.R. Vane, R.M. Bottling, Mechanism of action of anti inflammatory drugs, Int. J. Tissue React. 20 (1998) 3-15.

[76] A.P. Carvalho, C.M. Monteiro, F.X. Malcata, Simultaneous effect of irradiance and temperature on biochemical composition of the microalga Pavlova lutheri, J. Appl. Phycol. 21 (2009) 543-552. DOI 10.1007/s10811-009-9415-z

[77] G. Bonente, S. Pippa, S. Castellano, R. Bassi, M. Ballottari, Acclimation of Chlamydomonas reinhardtii to different growth irradiances, J. Biol. Chem. 287 (2012) 5833-5847. DOI: 10.1074/jbc.M111.304279

[78] Q. He, H. Yang, L. Wua, C. Hua, Effect of light intensity on physiological changes, carbon allocation and neutral lipid accumulation in oleaginous microalgae, Bioresource Technol. 191 (2015) 219-228. DOI: 10.1016/j.biortech.2015.05.021.

[79] V.S. Ferreira, R.F. Pinto, C. Sant'Anna, Low light intensity and nitrogen starvation modulate the chlorophyll content of Scenedesmus dimorphus, J. Appl. Microbiol. 120 (2016) 661-670. DOI: 10.1111/jam.13007.

[80] W.M. Darley, Chapter 3: Phytoplankton: environmental factors affecting growth, In: W.M. Darley (Ed.) Algal biology: a physiological approach, Blackwell Scientific Publications, Belgium, 1982, pp. 921-952.

[81] N. Mochizuki, R. Tanaka, B. Grimm, T. Masuda, M. Moulin, A.G. Smith, A. Tanaka, M.J. Terry, The cell biology of tetrapyrroles: a life and death struggle, Trends Plant Sci. 15 (2010) 488-498. DOI: 10.1016/j.tplants.2010.05.012. 


\section{Legends for Figures and Tables}

Figure 1 Changes of vegetative cell and cyst numbers in control, buffer treated $\left(10 \mathrm{~g} \mathrm{l}^{-1} \mathrm{Na}_{2} \mathrm{CO}_{3}\right)$ and nonsteroidal anti-inflammatory drug treated cultures of Haematococcus pluvialis A-B: diclofenac, C-D: diflunisal, E-F: mefenamic acid). Concentration values of the drugs (0.025-0.1) are in $\mathrm{mg} \mathrm{ml}^{-1}$. Data shown are means $+/-$ standard deviations, $n=3$. Different lowercase letters show significant differences among the tendencies of growth curves within a treatment $(\mathrm{p}<0.05)$. 

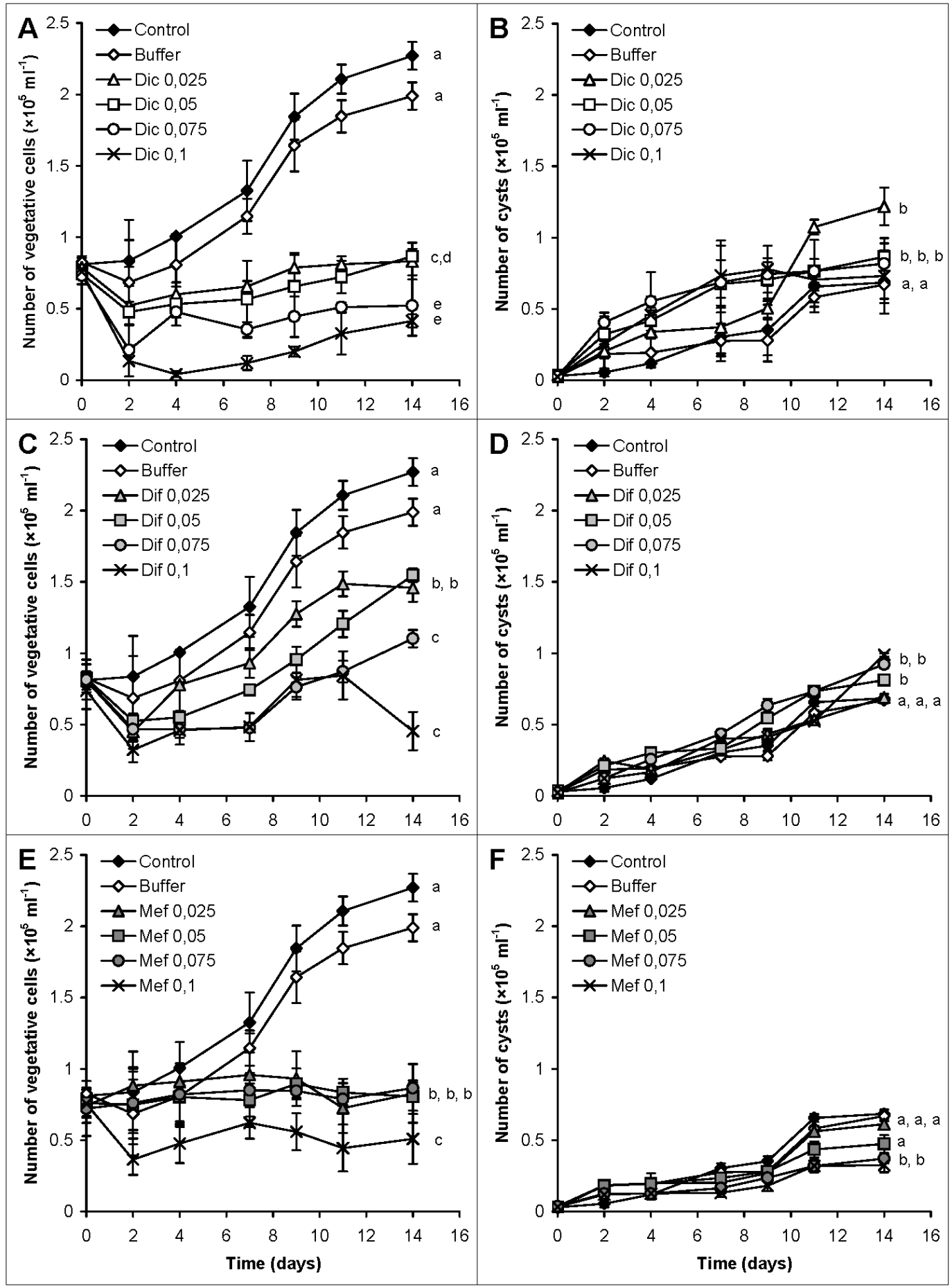
Figure 2 Qualitative characterization of carotenoid profile of mature cysts of the investigated Haematococcus pluvialis strain by HPLC-DAD investigation. The chromatograms were detected at $450 \mathrm{~nm}$, carotenoids were identified on the basis of their UV-VIS spectra, retention times in HPLC [56] and co-chromatography with authentic samples.

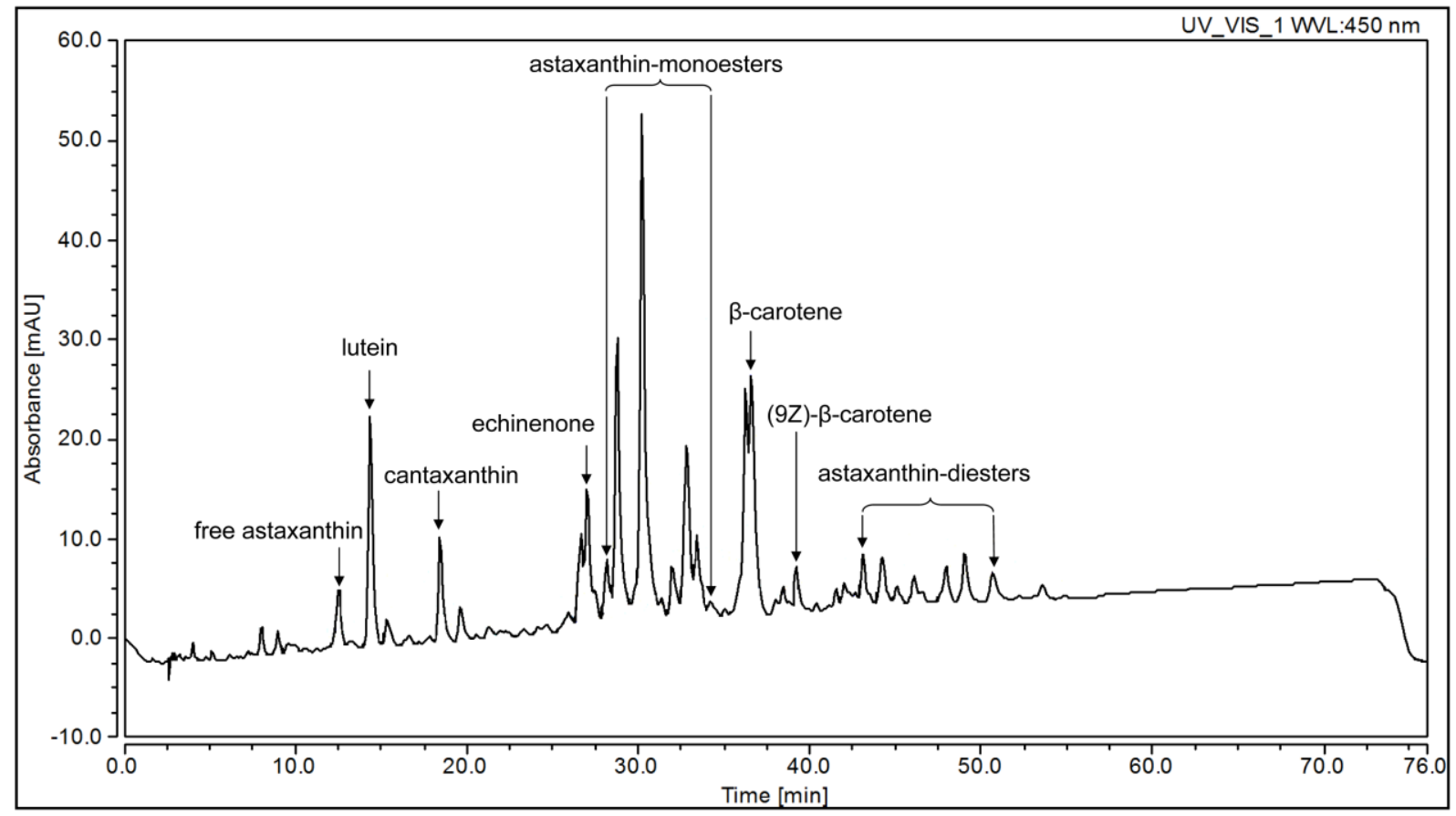


Figure 3 Spectrophotometric analysis of pigment compositions of three-month-old mature cysts (Old Cysts), and 28-day-old control and differently treated cultures of the investigated Haematococcus pluvialis strain. Induced: cultures with the addition of $0.01 \mathrm{mM} \mathrm{H}_{2} \mathrm{O}_{2}$ and $45 \mathrm{mM}$ sodium-acetate, Buffer: cultures with the addition of 10 $\mathrm{g} \mathrm{l}^{-1} \mathrm{Na}_{2} \mathrm{CO}_{3}$. Dic, Dif, and Mef: diclofenac, diflunisal and mefenamic acid, respectively. Concentration values of the drugs $(0.025-0.1)$ are in $\mathrm{mg} \mathrm{ml}^{-1}$. Data shown are means $+/$ - standard deviations, $\mathrm{n}=3$. Different lowercase letters show significant differences $(\mathrm{p}<0.05)$ among the pigment contents (subscripts: C: carotenoids; a: chlorophyll-a; b: chlorophyll-b).

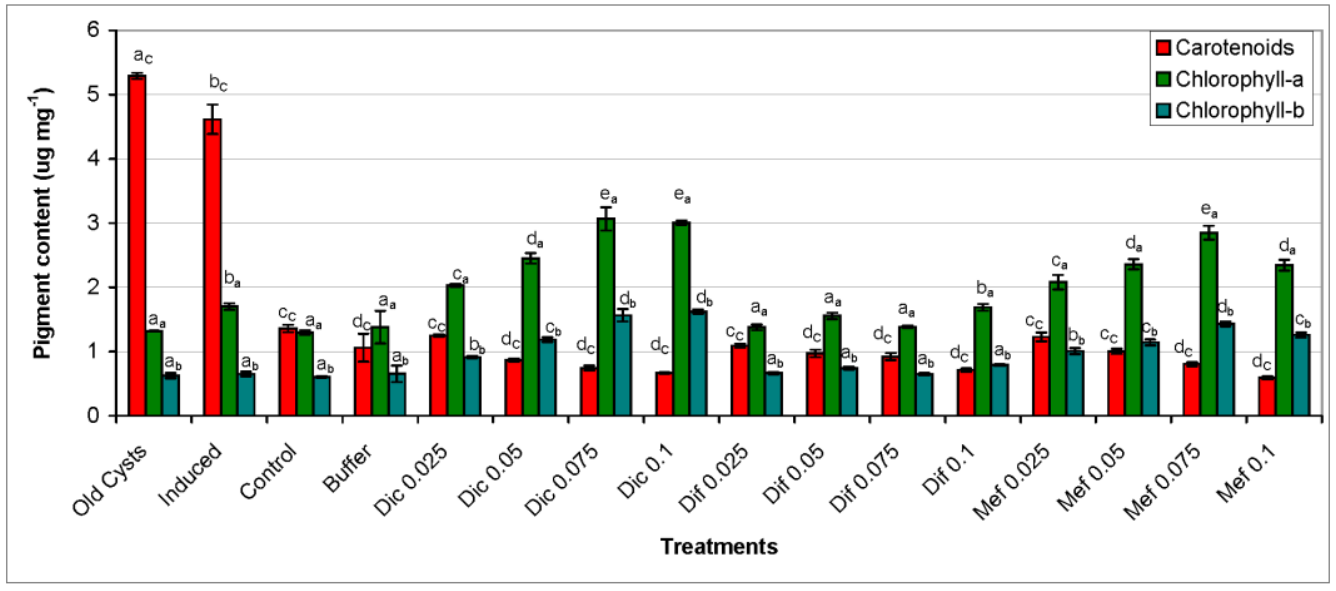


Figure 4 Thin layer chromatographic analysis of pigment compositions of three-month-old mature cysts (Old Cysts), and 28-day-old control and differently treated cultures of the investigated Haematococcus pluvialis strain. A: TLC plates: a: distance of astaxanthin standard from start line; b: distance of solvent front. $\mathrm{R}_{\mathrm{f}}$ was the value of a/b. 1-8: the identified peaks by CpAtlas; 1-3: chlorophylls and free astaxanthin; 4-7: astaxanthin monoand diesters; 8: $\beta$-carotene. B: Pigment content analysis based on peak area identified by CpAtlas. Induced: cultures with the addition of $0.01 \mathrm{mM} \mathrm{H}_{2} \mathrm{O}_{2}$ and $45 \mathrm{mM}$ sodium-acetate, Buffer: cultures with the addition of 10 $\mathrm{g}^{-1} \mathrm{Na}_{2} \mathrm{CO}_{3}$. Dic, Dif, and Mef: diclofenac, diflunisal and mefenamic acid, respectively. Concentration values of the drugs $(0.025-0.1)$ are in $\mathrm{mg} \mathrm{ml}^{-1}$. Data shown are means $+/-$ standard deviations, $\mathrm{n}=3$. Different lowercase letters show significant differences $(\mathrm{p}<0.05)$ among the pigment contents (subscripts: A: astaxanthin; $\beta$ : $\beta$ carotene; c: chlorophylls).

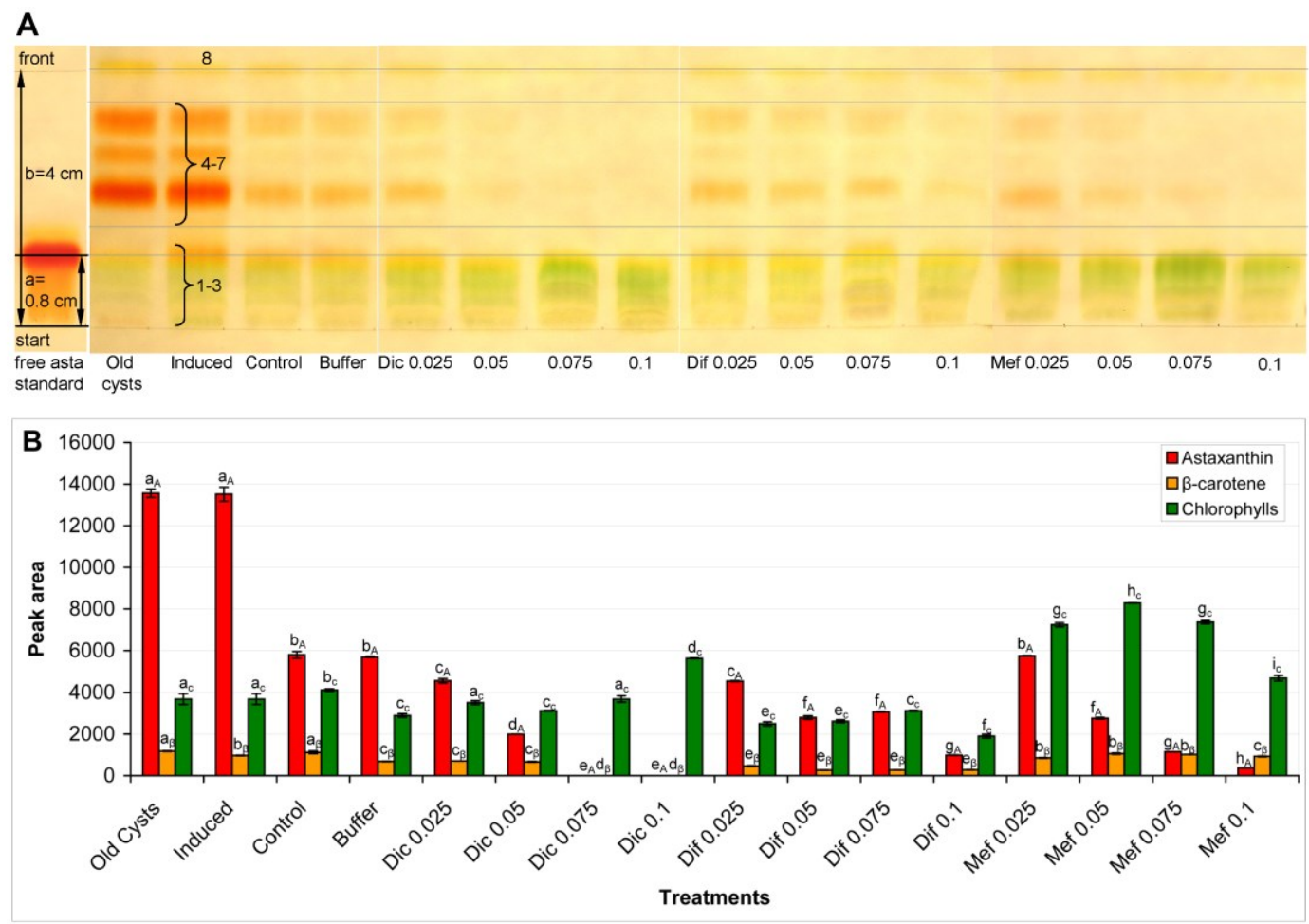


Table 1 Effective concentrations causing 50\% growth inhibition $\left(\mathrm{EC}_{50}\right.$ values) calculated for the different drugs for different exposition times on the basis of mean values of vegetative cell numbers and total cell numbers (vegetative cells and cysts together), considered growth as $100 \%$ in control or in buffer treated $\left(10 \mathrm{~g} \mathrm{l}^{-1} \mathrm{Na}_{2} \mathrm{CO}_{3}\right)$ culture.

\begin{tabular}{|c|c|c|c|c|c|}
\hline NSAID & $\begin{array}{l}\text { Calculation } \\
\text { method }\end{array}$ & Calculated to & $\begin{array}{l}96 \mathrm{hC}_{50} \\
\left(\mathrm{mg} \mathrm{ml}^{-1}\right)\end{array}$ & $\begin{array}{l}7 \mathrm{~d} \mathrm{EC}_{50} \\
\left(\mathrm{mg} \mathrm{ml}^{-1}\right)\end{array}$ & $\begin{array}{l}14 \mathrm{~d} \mathrm{EC}_{50} \\
\left(\mathrm{mg} \mathrm{ml}^{-1}\right)\end{array}$ \\
\hline \multirow{7}{*}{ Dic } & \multirow{3}{*}{ Control as $100 \%$} & Vegetative cell number & 0.053 & 0.037 & 0.029 \\
\hline & & & & & \\
\hline & & Total cell number & $0.103 *$ & $0.093 * *$ & 0.038 \\
\hline & \multirow{4}{*}{ Buffer as $100 \%$} & & & & \\
\hline & & Vegetative cell number & 0.069 & 0.044 & 0.033 \\
\hline & & & & & \\
\hline & & Total cell number & $0.1 * *$ & $0.13 *$ & $0.084 * *$ \\
\hline \multirow{7}{*}{ Dif } & \multirow{3}{*}{ Control as $100 \%$} & Vegetative cell number & 0.064 & 0.053 & 0.065 \\
\hline & & & & & \\
\hline & & Total cell number & $0.12 *$ & $0.093 * *$ & 0.03 \\
\hline & \multirow{4}{*}{ Buffer as $100 \%$} & & & & \\
\hline & & Vegetative cell number & 0.068 & 0.043 & 0.033 \\
\hline & & & & & \\
\hline & & Total cell number & $0.12 *$ & $0.13 *$ & n.c. \\
\hline \multirow{7}{*}{ Mef } & \multirow{3}{*}{ Control as $100 \%$} & Vegetative cell number & $0.102 *$ & $0.094 * *$ & 0.031 \\
\hline & & & & & \\
\hline & & Total cell number & $0.106^{*}$ & $0.093 * *$ & 0.038 \\
\hline & \multirow{4}{*}{ Buffer as $100 \%$} & & & & \\
\hline & & Vegetative cell number & $0.11^{*}$ & $0.12 *$ & 0.034 \\
\hline & & & & & \\
\hline & & Total cell number & $0.11 *$ & n.c. & 0.044 \\
\hline \multicolumn{6}{|c|}{ *: The calculated $\mathrm{EC}_{50}$ value was out of the studied range } \\
\hline \multicolumn{6}{|c|}{$\begin{array}{l}\text { **: Exact calculation was not possible based on the equations, due to the lack of concentration dependence of } \\
\text { measured toxicity }\end{array}$} \\
\hline \multicolumn{6}{|c|}{ n.c.: $\mathrm{EC}_{50}$ value was not calculable, because growth inhibition did not reach $50 \%$ in the studied concentration } \\
\hline
\end{tabular}


Table 2 Proportional data as \% of all separated peaks on the basis of peak area (Fig. 2), and structures of the main carotenoids in mature cysts of the investigated Haematococcus pluvialis strain.

\begin{tabular}{lcc}
\hline Main & Structure & Relative area \\
carotenoids & $(\%)$ \\
\hline
\end{tabular}

astaxanthin-

monoesters

astaxanthin-

diesters

free<smiles>[R]C1CC(C)(C)C(/C=C/C(C)=C/C=C/C(C)=C/C=C/C=C(C)/C=C/C=C(C)/C=C/C2=C(C)C(=O)C([R20])CC2(C)C)=CC1=O</smiles>

astaxanthin

$\beta$-carotene

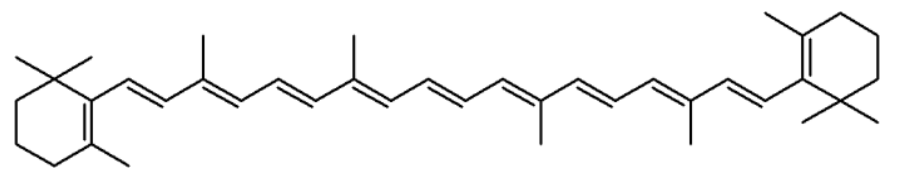

(9Z)- $\beta$ -

carotene<smiles>CC1=C(/C=C/C(C)=C/C=C/C(C)=C/C=C/C=C(C)/C=C/C=C(C)/C=C/C2=C(C)CCCC2(C)C)C(C)(C)CCC1</smiles>

lutein<smiles>CC1=C(/C=C/C(C)=C/C=C/C(C)=C/C=C/C=C(C)/C=C/C=C(C)/C=C/C2=CCC(O)CC2(C)C)C(C)(C)CC(O)C1</smiles>

cantaxanthin<smiles>CC1=C(/C=C/C(C)=C/C=C/C(C)=C/C=C/C=C(C)/C=C/C=C/C2=CC(=O)CCC2(C)C)C(C)(C)CCC1=O</smiles>

echinenone<smiles>CC1=C(/C=C/C(C)=C/C=C/C(C)=C/C=C/C=C(C)/C=C/C=C(C)/C=C/C2=C(C)C(=O)CCC2(C)C)C(C)(C)CCC1</smiles>

$\mathrm{R}^{1}$ and $\mathrm{R}^{2}$ are hydrogen and fatty acid chain, respectively in astaxanthin monoesters; fatty acid chains in astaxanthin diesters; and hydrogens in free astaxanthin. 
Table A1 Amounts ( $\mu \mathrm{g} \mathrm{mg}^{-1}$ ) of the two main primary carotenoids lutein and $\beta$-carotene of three-month-old mature cysts, and 28-day-old control and differently treated cultures of the investigated Haematococcus pluvialis strain. Data shown are the means $+/$ - standard deviations, $n=3$.

\begin{tabular}{lcc}
\hline Treatments & Main primary carotenoid content $\left(\mu \mathrm{g} \mathrm{mg}^{-1}\right)$ \\
\hline & Lutein & $\beta$-carotene \\
Old cysts & $0.215 \pm 0.008$ & $0.036 \pm 0.002$ \\
Induced & $0.106 \pm 0.01$ & $0.018 \pm 0.002$ \\
Control & $0.229 \pm 0.006$ & $0.063 \pm 0.003$ \\
Buffer & $0.342 \pm 0.01$ & $0.051 \pm 0.001$ \\
Dic 0.025 & $1.016 \pm 0.01$ & $0.139 \pm 0.014$ \\
Dic 0.05 & $1.049 \pm 0.009$ & $0.144 \pm 0.014$ \\
Dic 0.075 & $1.063 \pm 0.01$ & $0.128 \pm 0.012$ \\
Dic 0.1 & $0.465 \pm 0.012$ & $0.044 \pm 0.001$ \\
Dif 0.025 & $0.305 \pm 0.008$ & $0.052 \pm 0.002$ \\
Dif 0.05 & $0.613 \pm 0.011$ & $0.081 \pm 0.001$ \\
Dif 0.075 & $0.678 \pm 0.009$ & $0.101 \pm 0.001$ \\
Dif 0.1 & $0.284 \pm 0.01$ & $0.038 \pm 0.001$ \\
Mef 0.025 & $0.44 \pm 0.009$ & $0.072 \pm 0.002$ \\
Mef 0.05 & $0.608 \pm 0.008$ & $0.101 \pm 0.002$ \\
Mef 0.075 & $1.571 \pm 0.011$ & $0.166 \pm 0.011$ \\
Mef 0.1 & $0.607 \pm 0.007$ & $0.094 \pm 0.002$ \\
\hline
\end{tabular}

Old Cysts: three-month-old mature cysts

Induced: cultures with the addition of $0.01 \mathrm{mM} \mathrm{H}_{2} \mathrm{O}_{2}$ and $45 \mathrm{mM}$ sodium-acetate

Buffer: cultures with the addition of $10 \mathrm{~g} \mathrm{l}^{-1} \mathrm{Na}_{2} \mathrm{CO}_{3}$

Dic, Dif, and Mef: diclofenac, diflunisal and mefenamic acid, respectively. Concentration values of the drugs $(0.025-0.1)$ are in $\mathrm{mg} \mathrm{ml}^{-1}$ 


\section{Appendix}
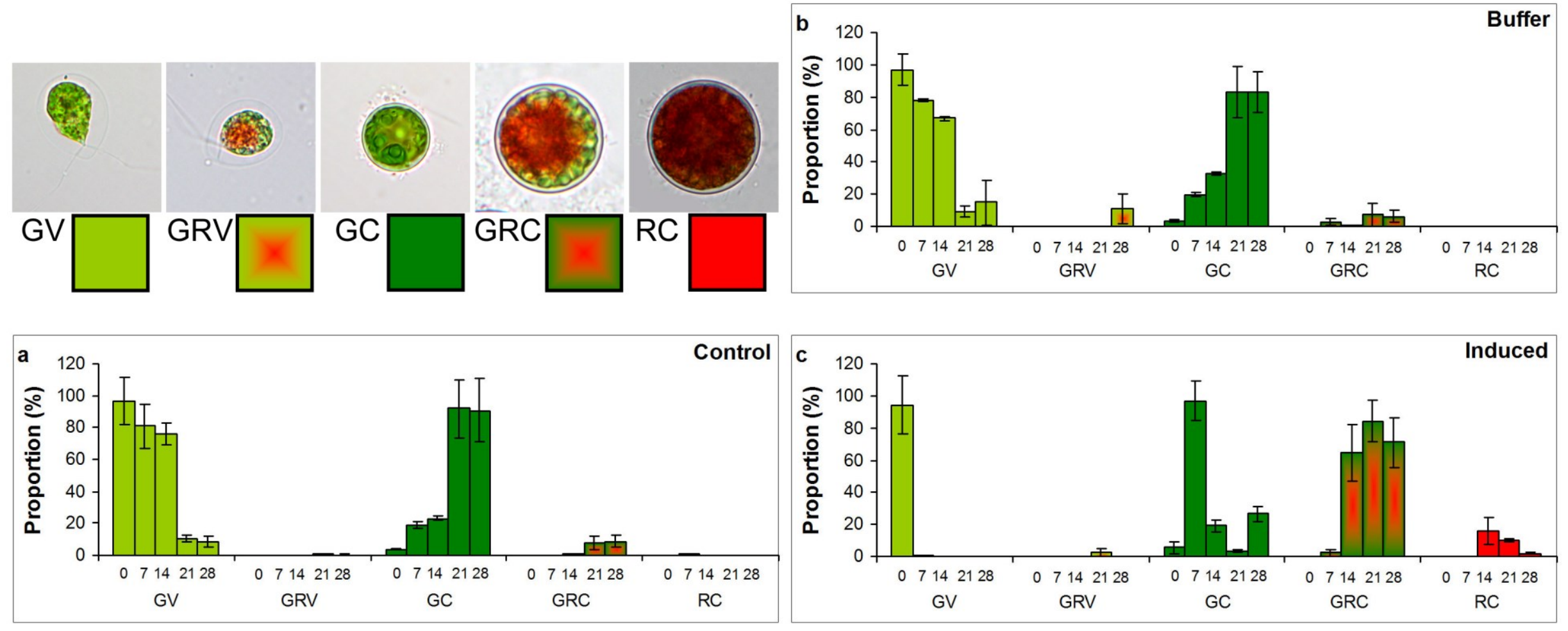

Figure A1 Cell type proportions (\%) in a) control, b) buffer treated $\left(10 \mathrm{~g} \mathrm{l}^{-1} \mathrm{Na}_{2} \mathrm{CO}_{3}\right)$, and c) induced $\left(0.01 \mathrm{mM} \mathrm{H} \mathrm{H}_{2}\right.$ and $45 \mathrm{mM}$ sodiumacetate) cultures of Haematococcus pluvialis on the $28^{\text {th }}$ day of experiments. Numbers on $\mathrm{x}$ axis mean the sampling days. GV: green vegetative (motile) cells; GRV: green-red vegetative (motile) cells; GC: green cysts (palmella stage); GRC: green-red cysts (intermediate stage); RC: red cysts (mature aplanospores). Data shown are means $+/-$ standard deviations, $n=3$. Photos in legends: $400 \times$ magnification, Olympus BX50F-3 fluorescent microscope, Olympus DP80 digital camera. 

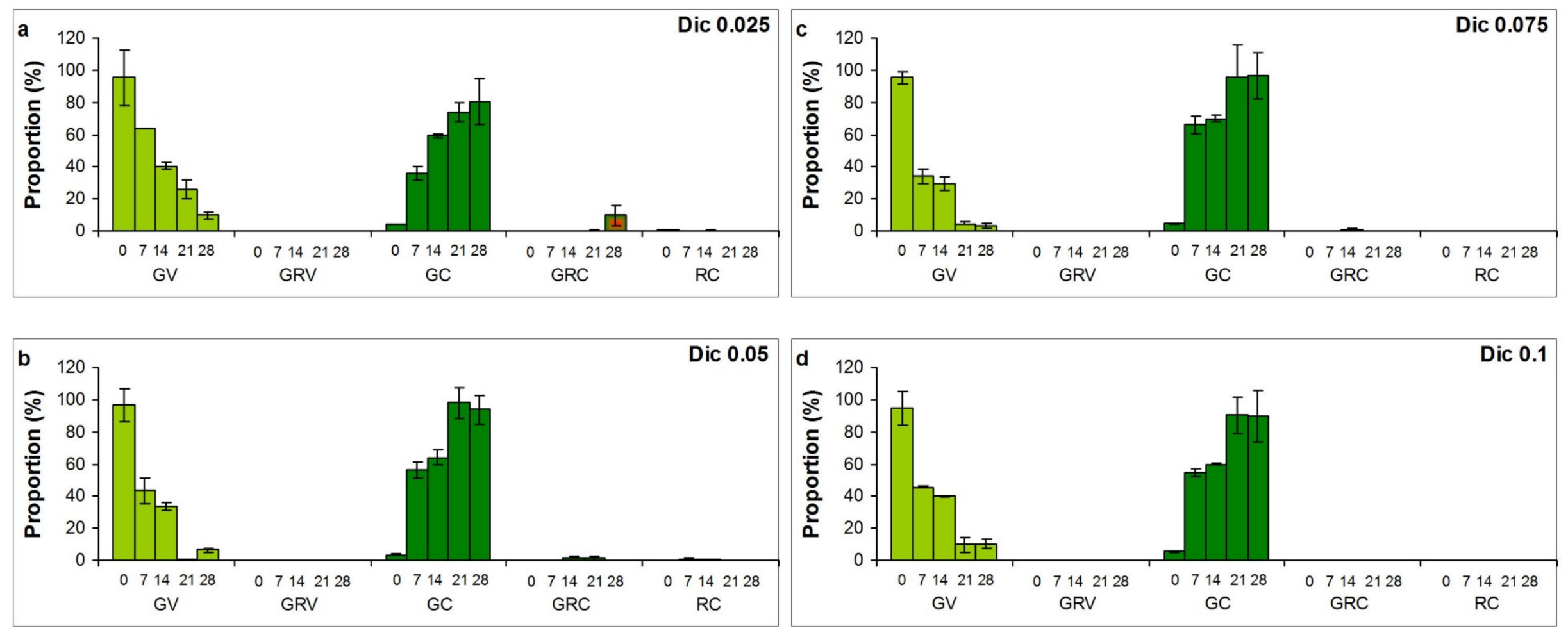

Figure A2 Cell type proportions (\%) in diclofenac (Dic) treated cultures of Haematococcus pluvialis on the $28^{\text {th }}$ day of experiments. Numbers on $\mathrm{x}$ axis mean the sampling days. a) 0.025 ; b) 0.05 ; c) 0.075 and d) $0.1 \mathrm{mg} \mathrm{ml}^{-1}$ Dic treatment. GV: green vegetative (motile) cells; GRV: green-red vegetative (motile) cells; GC: green cysts (palmella stage); GRC: green-red cysts (intermediate stage); RC: red cysts (mature aplanospores; see legends for Fig. A1). Data shown are means + - standard deviations, $\mathrm{n}=3$. 

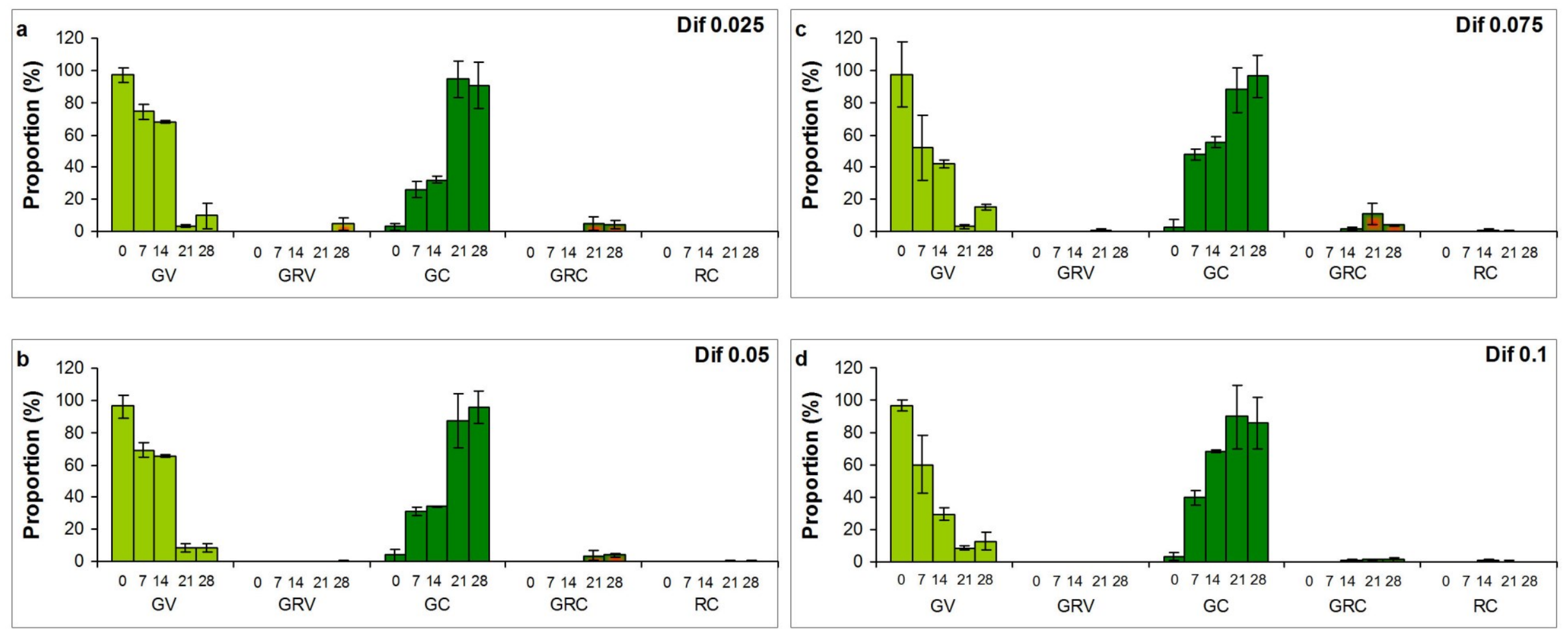

Figure A3 Cell type proportions (\%) in diflunisal (Dif) treated cultures of Haematococcus pluvialis on the $28^{\text {th }}$ day of experiments. Numbers on $\mathrm{x}$ axis mean the sampling days. a) 0.025 ; b) 0.05 ; c) 0.075 and d) $0.1 \mathrm{mg} \mathrm{ml}^{-1}$ Dif treatment. GV: green vegetative (motile) cells; GRV: green-red vegetative (motile) cells; GC: green cysts (palmella stage); GRC: green-red cysts (intermediate stage); RC: red cysts (mature aplanospores; see legends for Fig. A1). Data shown are means $+/$ - standard deviations, $n=3$. 

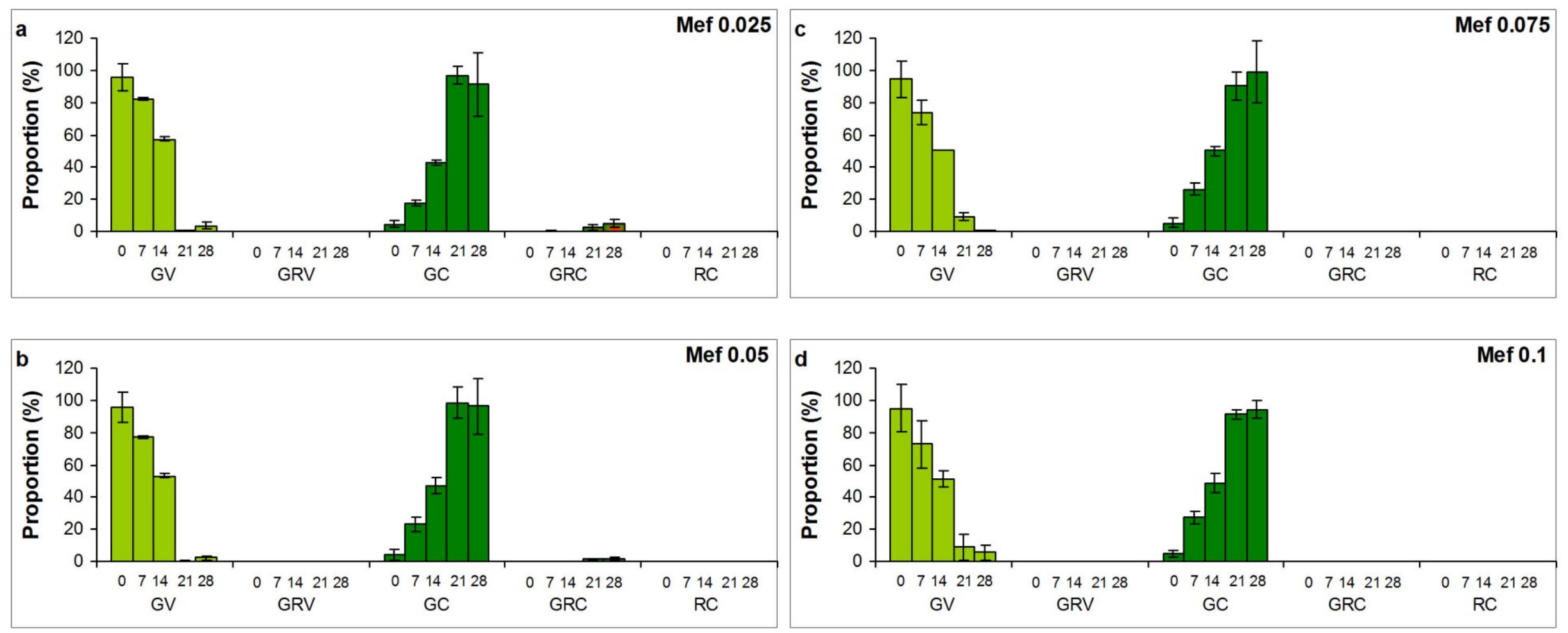

Figure A4 Cell type proportions (\%) in mefenamic-acid (Mef) treated cultures of Haematococcus pluvialis on the $28^{\text {th }}$ day of experiments.

Numbers on $\mathrm{x}$ axis mean the sampling days. a) 0.025 ; b) 0.05 ; c) 0.075 and d) $0.1 \mathrm{mg} \mathrm{ml}^{-1}$ Mef treatment. GV: green vegetative (motile) cells; GRV: green-red vegetative (motile) cells; GC: green cysts (palmella stage); GRC: green-red cysts (intermediate stage); RC: red cysts (mature aplanospores; see legends for Fig. A1). Data shown are means $+/$ - standard deviations, $\mathrm{n}=3$. 
